\title{
Electronic Energy Levels in High-Temperature Superconductors
}

\author{
H.P. Roeser • D.T. Haslam • J.S. López • M. Stepper • \\ M.F. von Schoenermark • F.M. Huber • \\ A.S. Nikoghosyan
}

Received: 21 August 2010 / Accepted: 29 August 2010 / Published online: 24 September 2010

(C) The Author(s) 2010. This article is published with open access at Springerlink.com

\begin{abstract}
Parent materials of high-temperature superconductors (HTSC) need to be doped to become superconducting. The optimum doping for maximum critical transition temperature $T_{\mathrm{c}}$ has been analyzed for more than 20 materials. Assuming a uniform doping distribution the distance $x$ between doped unit cells-projected into the $\mathrm{CuO}_{2}$ plane for cuprates-shows a strong linear correlation to the inverse of $T_{\mathrm{c}}$ in the form $(2 x)^{2}=m_{1} 1 / T_{\mathrm{c}}$ with a slope of $m_{1}=$ $(2.786 \pm 0.029) \times 10^{-15} \mathrm{~m}^{2} \mathrm{~K}$. The mercury cuprate homologous series $\mathrm{HgBa}_{2} \mathrm{Ca}_{n-1} \mathrm{Cu}_{n} \mathrm{O}_{2 n+2+\delta}$ with $n=1,2,3$ has been used to demonstrate the procedure deriving the doping distance $x$ from the optimum doping value $\delta$.
\end{abstract}

Keywords High-temperature superconductor .

Superconductor crystal structure - Superconducting current channel $\cdot$ Superconducting unit area

\section{Introduction}

High-temperature superconductors (HTSC) are known since the discovery by Bednorz and Müller in 1986 and the number of different HTSC materials is still increasing. Modern

H.P. Roeser $(\bowtie)$ · D.T. Haslam · J.S. López · M. Stepper

Institute of Space Systems, University of Stuttgart,

Pfaffenwaldring 31, 70569 Stuttgart, Germany

e-mail: roeser@irs.uni-stuttgart.de

M.F. von Schoenermark - F.M. Huber

German Aerospace Center, GSOC, Muenchnerstr. 20,

82234 Wessling, Germany

A.S. Nikoghosyan

Department of Microwave and Telecommunication, Yerevan State

University, Alex Manoogian 1, Yerevan, 0025, Armenia techniques allow very detailed investigations even down to the atomic level within the unit cell of a HTSC crystal. Nevertheless the physical phenomenon is still not fully understood.

One important aspect is the role of optimum doping to achieve the maximum critical transition temperature $T_{\mathrm{c}}$. For example, varying in cuprates the oxygen content or the heat treatment of the materials dramatically change their transition temperatures, critical current densities, magnetic fields and other properties.

This paper is an attempt to establish a link between $T_{\mathrm{c}}$ and the doping and crystal structure in HTSC materials.

\section{Crystal Structure and Particle in the Box Concept}

The energy level estimate for electronic excitation in an atom is given by

$E=\frac{h^{2}}{8 m_{\mathrm{e}}\left(d_{\mathrm{A}}\right)^{2}} \approx 6.7 \times 10^{-19} \mathrm{~J} \approx 4 \mathrm{eV}$

where $m_{\mathrm{e}}$ is the electron mass and $\mathrm{d}_{\mathrm{A}}$ the atomic diameter leading to a typical value of $4 \mathrm{eV}$ for $d_{\mathrm{A}}=0.3 \mathrm{~nm}$ [1]. Equation (1) can be considered as the lowest energy level $E_{1}$ of a particle in a box $(\mathrm{PiB})$ with a quantum well width equal to the diameter of the atom.

The parent materials of high-temperature superconductors, e.g. cuprates, are usually electrical insulators. They resist the flow of electric current because their valence electrons are tightly bonded to their atoms. Therefore, these materials should show no electronic excitation for conducting electrons or holes, but only the electronic excitation in an atom. A very well studied example is the anti-ferromagnetic insulator $\mathrm{La}_{2} \mathrm{CuO}_{4}$, which is the parent compound of many HTSCs. This ternary compound becomes superconducting 
by doping with an alkaline earth metal $(\mathrm{Ba}, \mathrm{Sr}, \mathrm{Ca}, \mathrm{Na}$, $\mathrm{K}, \ldots$ ) and/or introduction of oxygen deficiency or interstitial oxygen excess within the crystal. It is well known that these measures create $\mathrm{Cu}^{3+}$-ions in the $\mathrm{CuO}_{2}$ plane of the doped unit cell of cuprates being partly responsible for superconducting carriers with mass $M_{\mathrm{eff}}=2 m_{\mathrm{e}}$. This is true for p-type (e.g. hole-doped $\mathrm{La}_{2-\Delta} \mathrm{Ca}_{1+\Delta} \mathrm{Cu}_{2} \mathrm{O}_{6+\delta}$ ) as well as n-type (e.g. electron-doped $\mathrm{Pr}_{1-\Delta} \mathrm{LaCe}_{\Delta} \mathrm{CuO}_{4-\delta}$ ) HTSCs.

Detailed measurements have been done for most of the HTSCs to optimize the doping for maximum $T_{\mathrm{c}}$. It has been found that for each HTSC a homogeneous doping distribution is necessary and that there exist an optimum doping level with a parabolic decrease in $T_{\mathrm{c}}$ for lower and higher doping levels forming a bell-shaped curve. These doped materials are now conductors and therefore should show an electronic excitation for conducting electrons or holes. In this case the energy level estimate for a HTSC should read in analogy to (1)

$E_{1} \approx \frac{h^{2}}{8 M_{\mathrm{eff}} x^{2}}=3.3 \times 10^{-21} \mathrm{~J} \approx 20 \mathrm{meV}$

where $x$ is the distance between doped unit cells projected into the superconducting $\mathrm{CuO}_{2}$ plane for cuprates. This leads to a typical value of $20 \mathrm{meV}$ for $x=3 \mathrm{~nm}$ and $M_{\text {eff }}=2 m_{\mathrm{e}}$ (see Sect. 4). Crystals built by tetragonal unit cells prefer to form a square homogeneous doping distribution whereas crystals built by orthorhombic unit cells could also form a hexagonal homogeneous doping distribution $[2,3]$. In both cases the doping pattern in the $\mathrm{CuO}_{2}$ plane offers straight lines or arrays of equidistant doped unit cells throughout the whole crystal. Therefore the electronic excitation could be related to the ground state $E_{1}$ of a 1-dimensional particle in the box $(\mathrm{PiB})$, which scales with the size of the doping separation $x$.

Equation (2) contains only one particle in the box, which ignores the fact that multi-layered $\mathrm{CuO}_{2}$ planes $(n>1)$ per chemical formula offer even higher critical transition temperatures than single $\mathrm{CuO}_{2}$-layer cuprates. A simple approach to account for this is the analogy between (2) and the Fermi energy $E_{\mathrm{F}}$ and its relation to the carrier density $N_{\mathrm{c}}$ given by

$E_{\mathrm{F}}=\frac{h^{2}}{8 M_{\mathrm{eff}}} N_{\mathrm{c}}^{2 / 3}\left[\frac{3}{\pi}\right]^{2 / 3}$

If the carrier density increases by a factor $n$, the Fermi energy increases by $E_{\mathrm{F}} \sim\left(n N_{\mathrm{c}}\right)^{2 / 3}=n^{2 / 3}\left(N_{\mathrm{c}}\right)^{2 / 3}$. This transforms (2) into

$E_{1} \approx \frac{h^{2} n^{2 / 3}}{8 M_{\mathrm{eff}} x^{2}}$
On the other hand, a superconductor is characterized by its transition temperature $T_{\mathrm{c}}$ and the thermal energy of the crystal $E_{\text {th }}$ related to it. Therefore, $E_{\text {th }}$ is a function of $k T_{\mathrm{c}}$ expressed by $E_{\mathrm{th}}=f\left(k T_{\mathrm{c}}\right)$. We are interested in a correlation between $E_{\text {th }}$ and the energy $E_{1}$, which is given by the doping separation $x$ in a straight line of equidistant doped unit cells through the whole crystal. Thus, $E_{1}$ is replaced by $f\left(k T_{\mathrm{c}}\right)$ and (4) can be written as

$(2 x)^{2} n^{-2 / 3}=\frac{h^{2}}{2 M_{\text {eff }} f\left(k T_{\mathrm{c}}\right)}$

In the following, more than 20 HTSC materials will be analyzed by plotting $(2 x)^{2} n^{-2 / 3}$ versus $1 / T_{\mathrm{c}}$. The doping separation $x$ will be derived from the experimentally determined optimum doping for maximum $T_{\mathrm{c}}$. The procedure for the analysis will be described in detail for the HTSC family $\mathrm{HgBa}_{2} \mathrm{Ca}_{n-1} \mathrm{Cu}_{n} \mathrm{O}_{2 n+2+\delta}$.

\section{HBCCO Family}

Since the discovery of $\mathrm{HgBa}_{2} \mathrm{CuO}_{4+\delta}$ in 1993 [4], which is the first member of the Mercury cuprate homologous series $\mathrm{HgBa}_{2} \mathrm{Ca}_{n-1} \mathrm{Cu}_{n} \mathrm{O}_{2 n+2+\delta}$, a lot of effort has been spent to prepare bulk samples of $\mathrm{HBCCO}$ containing up to $n=6$ layers of $\mathrm{CuO}_{2}$. At normal pressure the mercury based component with $n=3$ exhibits the highest $T_{\mathrm{c}} \approx 135 \mathrm{~K}$. Therefore this HTSC family has been studied in great detail by many research groups to get insight into understanding HTSCs towards the achievement of hopefully higher transition temperatures [5].

The structural arrangements of the first three members of this family are illustrated in Figs. 1, 4 and 6. For all members the crystal structure is tetragonal and the $\mathrm{CuO}_{2}$ planes are super flat [6]. The cell parameters and the doping levels at $T_{\mathrm{c}}$ or below have been used because in particular the doping values could change significantly from $T=300 \mathrm{~K}$ down to $T<T_{\mathrm{c}}$. The synthesis and the quality of preparation for the different members of the $\mathrm{Hg}$-family are very important to avoid transition temperatures which are caused

(a) by a mixture or the intergrowths e.g. of $\mathrm{Hg}-1212$ and $\mathrm{Hg}-1223$ and

(b) by multi doped members like $\mathrm{Hg}_{0.98} \mathrm{Ba}_{2.01} \mathrm{Ca}_{1.01}$ $\mathrm{Cu}_{2.00} \mathrm{O}_{6+\delta}$ [7],

instead of being the result of a pure single phase. The oxygen above $\mathrm{O}_{2 n+2}$ stoichiometry is located in the $\mathrm{Hg}$ layers as shown in Figs. 1, 4 and 6.

\section{$4 \mathrm{Hg}-1201$}

Figure 1 shows the tetragonal crystal structure of a singlephase $\mathrm{HgBa}_{2} \mathrm{CuO}_{4+\delta 1}$. The interstitial oxygen excess atom 
is placed in the $\mathrm{Hg}$ plane that forms the top and bottom of the unit cell $\left(\mathrm{HgO}_{\delta}\right)$. Synthesizing single-phase $\mathrm{Hg}-1201 \mathrm{com}-$ pounds with various oxygen contents over a range of 4.034.14 showed a maximum $T_{\mathrm{c}}=95 \pm 1 \mathrm{~K}$ at an optimized doping level of $\delta_{1} \approx 0.08$ [4, 8]. The excess oxygen was homogeneously distributed.

The undoped $\mathrm{Hg}-1201$ unit cell contains four oxygen atoms $\left(4 \mathrm{O}^{2-}\right)$, which require eight electrons resulting in the electronic configuration $1 \mathrm{Hg}^{2+}+2 \mathrm{Ba}^{2+}+1 \mathrm{Cu}^{2+}+4 \mathrm{O}^{2-}$. This material has no $\mathrm{Cu}^{3+}$-element and is not superconducting unless it is doped with an additional oxygen atom.

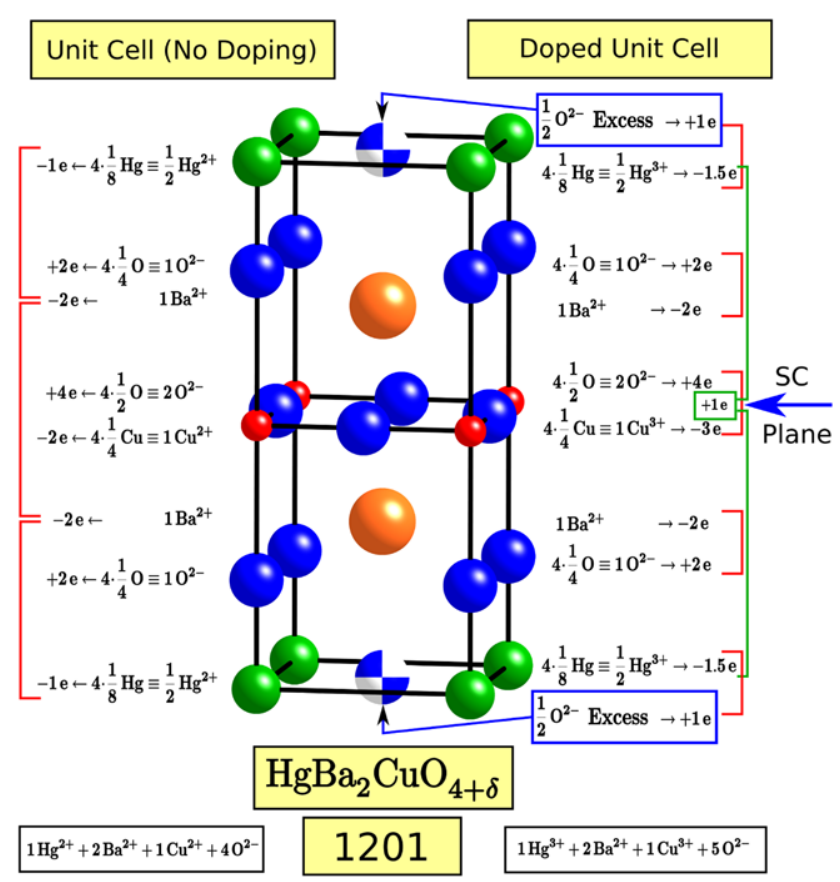

Fig. 1 Unit cell of $\mathrm{Hg}-1201$ illustrating the pure and oxygen doped electronic configuration
A doped unit cell with $\mathrm{HgBa}_{2} \mathrm{CuO}_{5}$ needs two more electrons, which are provided by transforming $\mathrm{Hg}^{2+}$ into $\mathrm{Hg}^{3+}$ and $\mathrm{Cu}^{2+}$ into $\mathrm{Cu}^{3+}$ because $\mathrm{Hg}^{3+}$ and $\mathrm{Cu}^{3+}$ are the next elements in line with the lowest ionization energy (Fig. 2). This effect is described in literature as charge transfer from $\mathrm{HgO}_{\delta}$ to $\mathrm{CuO}_{2}$ planes. The $\mathrm{HgO}_{\delta}$ plane is considered to act as "charge reservoir" and the oxygen excess is "doping" $\mathrm{Cu}^{3+}$-holes into the $\mathrm{CuO}_{2}$ plane.

A uniform distribution of doped unit cells with oxygen excess atoms arrange in a square distribution of $\mathrm{Cu}^{3+}$ ions in the $\mathrm{CuO}_{2}$ plane. The distance between two $\mathrm{Cu}^{3+}$ ion positions is always given by $x_{1}^{2}=\left(z_{1}^{2}+z_{2}^{2}\right) a^{2}$ with $z_{1}, z_{2}=0,1,2, \ldots$ and the lattice constant a forming an HTSC unit area of $\left(z_{1}^{2}+z_{2}^{2}\right)=\Sigma$ of $\mathrm{CuO}_{2}$ unit elements [ 3 and references therein]. The HTSC unit area has four doped unit cells with $\mathrm{Cu}^{3+}$-ions at its corners counting as one doped element, and the doping density is thus given by $(\Sigma)^{-1}$. The optimum oxygen excess value is derived from the bell-shaped $T_{\mathrm{c}}$ versus $\delta_{1}$ curve, which is centered at $\delta_{1}=0.0825 \pm 0.005$ [8]. This results in a doping density of $(\Sigma)^{-1}=\left(4+\delta_{1}\right) / 4-1 \equiv 2.06 \%$. According to the square pattern distribution for tetragonal unit cells $\Sigma$ should by formed by $\Sigma=48.5 \approx\left(z_{1}^{2}+z_{2}^{2}\right)=\left(7^{2}+0^{2}\right)=49$ $\mathrm{CuO}_{2}$ unit elements. Therefore the doping distance results in $x_{1}=\sqrt{ } 49 a=2.71 \times 10^{-9} \mathrm{~m}$.

The length $x_{1}$ can also be calculated via the diagonal of the $\mathrm{CuO}_{2}$ unit area by $x_{1}^{2}=\left(z_{3} a \sqrt{ } 2\right)^{2}+\left(z_{4} a \sqrt{ } 2\right)^{2}=$ $\left(2 \times 3.5^{2}+2 \times 3.5^{2}\right) a^{2}$ with $z_{3}=z_{4}=3.5$. The analysis, mentioned in Sect. 2 for $n=1$, results in $(2 x)^{2} n^{-2 / 3} T_{\mathrm{c}}=$ $2.79 \times 10^{-15} \mathrm{~m}^{2} \mathrm{~K}$. Figure 3 shows the superconducting $\mathrm{CuO}_{2}$ plane and the distribution of the unit cells with $\mathrm{Cu}^{3+}$-ions. The distribution of the oxygen excess atoms has the same pattern in the $\mathrm{Hg}$ plane exactly above and below.
Fig. 2 Ionization energy levels of the different atoms in $\mathrm{HgBa}_{2} \mathrm{Ca}_{n-1} \mathrm{Cu}_{n} \mathrm{O}_{2 n+2+\delta}$

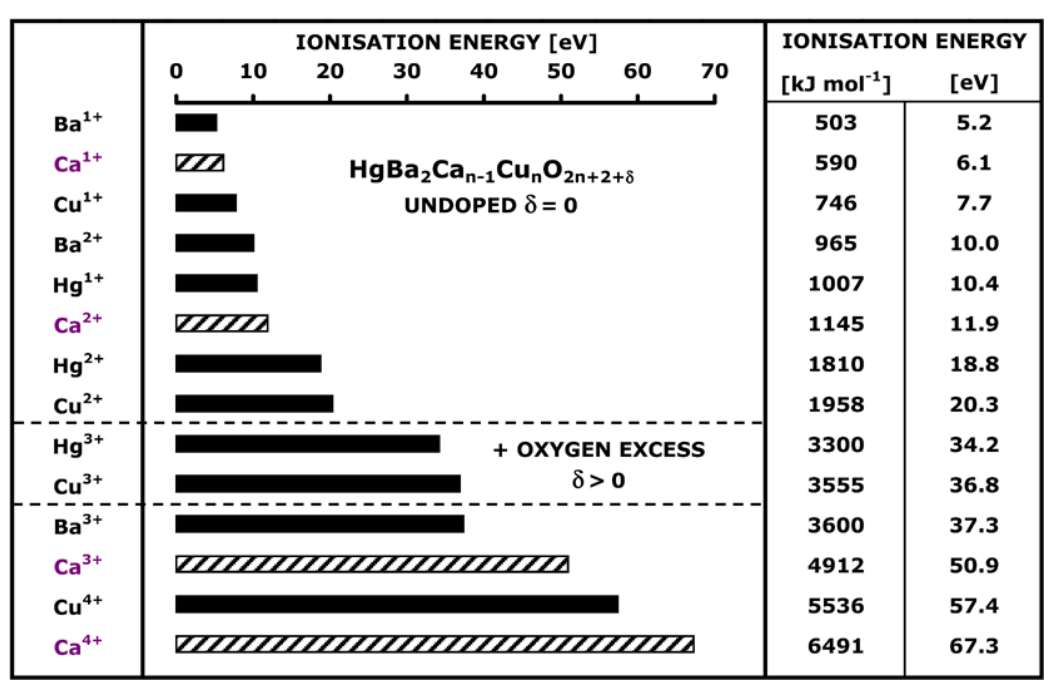


Fig. 3 Homogeneous doping distribution of $\mathrm{Hg}-1201$ with $\delta=0.08$ in the $\mathrm{CuO}_{2}$ plane. The linear array of doped unit cells forms superconducting unit areas with four doped unit cells at each corner and superconducting current channels

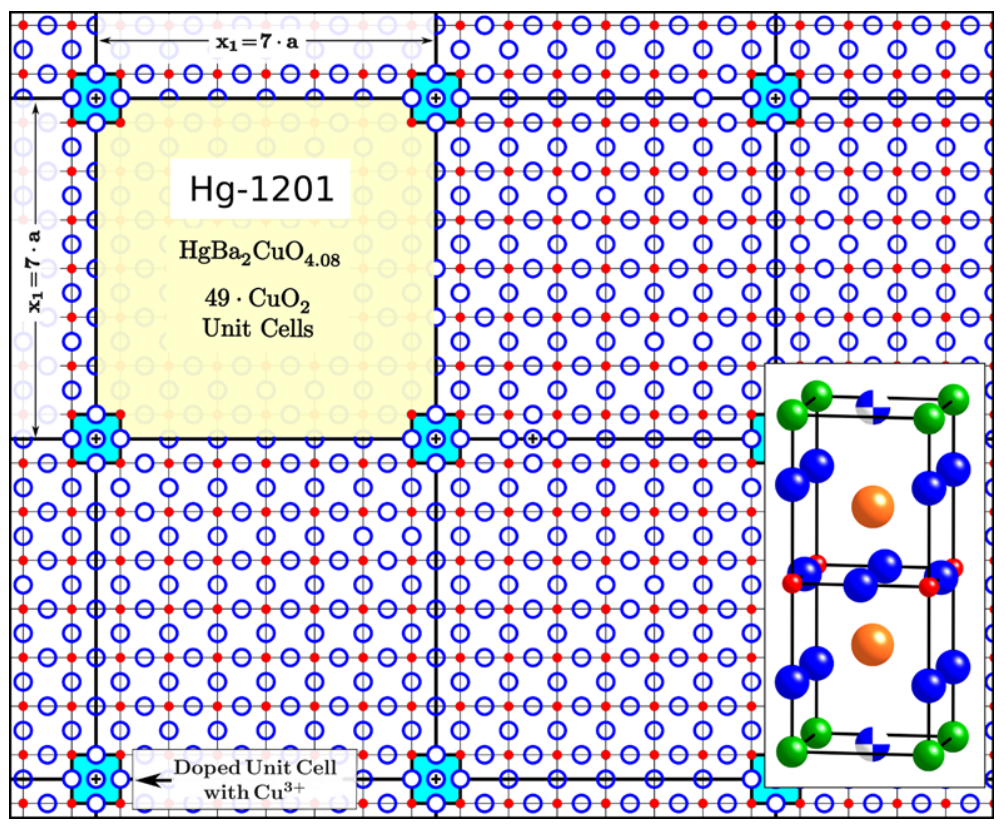

\section{$5 \mathrm{Hg}-1212$}

Figure 4 shows the tetragonal crystal structure of a singlephase $\mathrm{HgBa}_{2} \mathrm{CaCu}_{2} \mathrm{O}_{6+\delta 2}$ (Hg-1212). Again, the interstitial oxygen excess atom is placed in the $\mathrm{Hg}$ plane. The undoped $\mathrm{Hg}-1212$ unit cell contains six oxygen atoms $\left(6 \mathrm{O}^{2-}\right)$, which require 12 electrons resulting in the electronic configuration $1 \mathrm{Hg}^{2+}+2 \mathrm{Ba}^{2+}+1 \mathrm{Ca}^{2+}+2 \mathrm{Cu}^{2+}+6 \mathrm{O}^{2-}$ with two $\mathrm{CuO}_{2}$ planes. This material has no $\mathrm{Cu}^{3+}$-element and is not superconducting unless it is doped with an additional oxygen atom. Doping a unit cell with one oxygen atom transforms the electronic configuration into $1 \mathrm{Hg}^{3+}+$ $2 \mathrm{Ba}^{2+}+1 \mathrm{Ca}^{2+}+1 \mathrm{Cu}^{2+}+1 \mathrm{Cu}^{3+}+7 \mathrm{O}^{2-}$ and only one $\mathrm{CuO}_{2}$ plane contains a $\mathrm{Cu}^{3+}$-ion. Because there is no preference for one of the two $\mathrm{CuO}_{2}$ planes the $\mathrm{Cu}^{3+}$-ion will alternate between the two $\mathrm{CuO}_{2}$ planes. This means that half of the oxygen doping will serve the upper $\mathrm{CuO}_{2}$ plane and the other half the lower plane. Therefore the $\mathrm{Cu}^{3+}$-ion doping density for one $\mathrm{CuO}_{2}$ plane will be determined by $0.5 \Sigma^{-1}=0.5\left[\left(6+\delta_{2}\right) / 6-1\right]$. Assuming a homogeneously oxygen excess doping distribution in the $\mathrm{Hg}$ plane given by $\Sigma^{-1}$ results in a square oxygen excess doping distance $d_{2}$ with $\left(d_{2}\right)^{2}=\Sigma a^{2}=\left(z_{1}^{2}+z_{2}^{2}\right) a^{2}$. The square doping distribution of $\mathrm{Cu}^{3+}$-ions in each $\mathrm{CuO}_{2}$ plane will be given by $\left(x_{2}\right)^{2}=\left(z_{3}^{2}+z_{4}^{2}\right) a^{2}$ with the relation $x_{2}=\sqrt{ } 2 d_{2}$ as illustrated in Fig. 5. Therefore the two doping distributions result in the relation $\left(z_{3}^{2}+z_{4}^{2}\right)=2\left(z_{1}^{2}+z_{2}^{2}\right)$ with a strong restriction by choosing appropriate $z_{1}$ to $z_{4}$ numbers.

The transition temperatures for single-phase Hg-1212 reported in literature have a relatively sharp value of $126 \pm$ $1.5 \mathrm{~K}[6,9-12]$, whereas the oxygen doping varies by $\delta_{2}=0.21 \pm 0.01$ probably caused by the bell-shaped $T_{\mathrm{c}}$

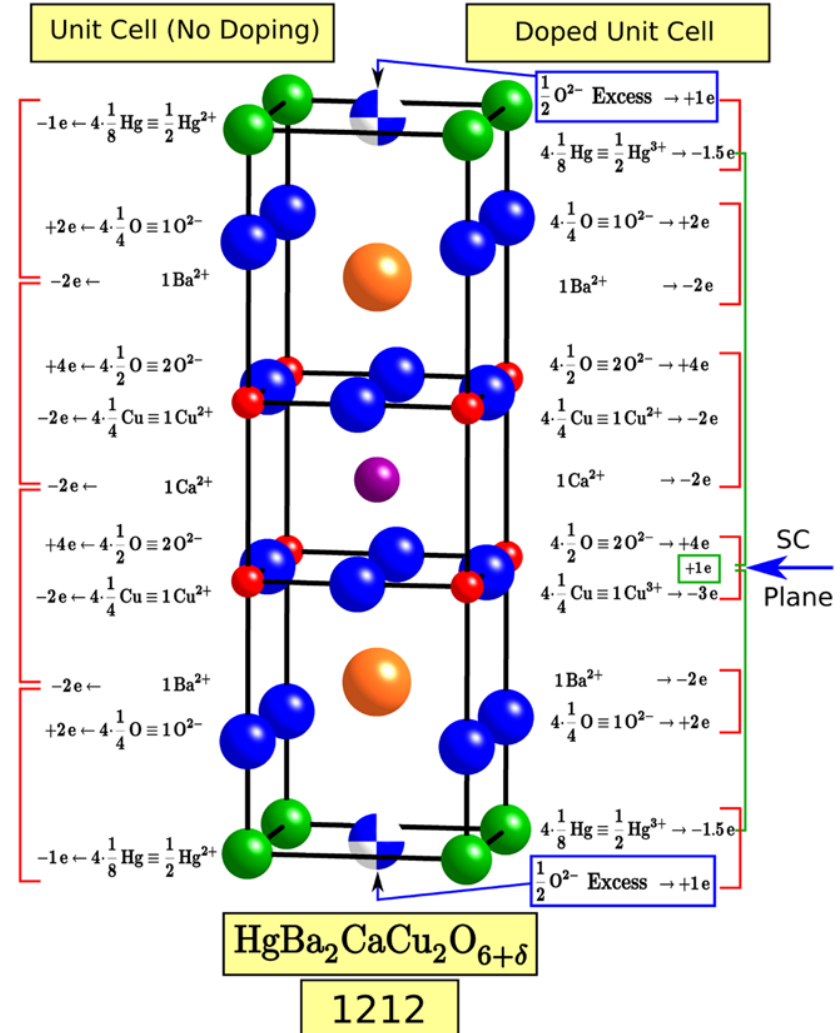

$1 \mathrm{Hg}^{2+}+2 \mathrm{Ba}^{2+}+1 \mathrm{Ca}^{2+}+2 \mathrm{Cu}^{2+}+6 \mathrm{O}^{2-}$

Fig. 4 Unit cell of Hg-1212 illustrating the pure and oxygen doped electronic configuration. The $\mathrm{Cu}^{3+}$-ion will alternate between the two $\mathrm{CuO}_{2}$ planes resulting in two superconducting $\mathrm{CuO}_{2}$ planes

versus $\delta_{2}$ curve. This results in a density for oxygen excess of $\Sigma^{-1}=3.50 \times 10^{-2}$ or $\Sigma=28.6 \approx 29=\left(5^{2}+2^{2}\right)$ 
Fig. 5 Red and filled circles represent the $\mathrm{Cu}^{3+}$-ion distribution in the upper $\mathrm{CuO}_{2}$ plane, green and open circles represent the $\mathrm{Cu}^{3+}$-ion distribution in the lower $\mathrm{CuO}_{2}$ plane of $\mathrm{Hg}-1212$. Both together represent the oxygen excess distribution in the $\mathrm{Hg}$ plane separated by $d_{2}$. The $\mathrm{Cu}^{3+}$-ion separation is given by $x_{2}=\sqrt{ } 2 d_{2}$

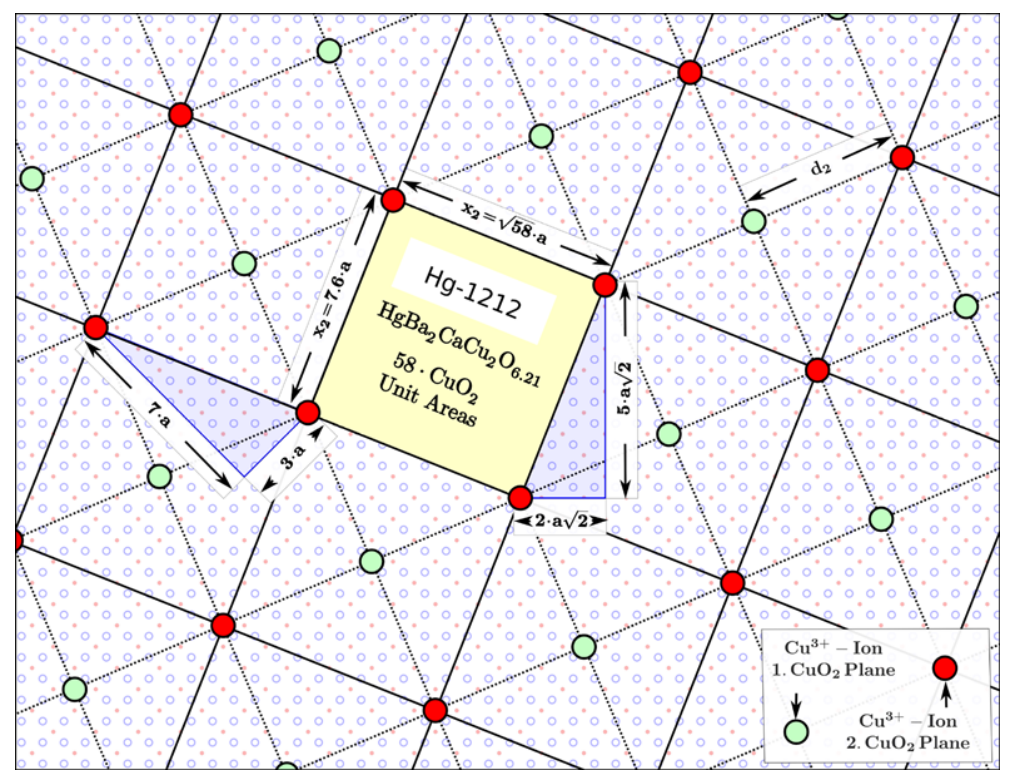

and $d_{2}=\sqrt{ } 29 a=2.08 \times 10^{-9} \mathrm{~m}$. The $\mathrm{Cu}^{3+}$-ion distribution per $\mathrm{CuO}_{2}$ plane is given by $x_{2}=\sqrt{ } 2 d_{2}=\sqrt{ } 58 a=$ $\sqrt{ }\left(7^{2}+3^{2}\right) a=2.94 \times 10^{-9} \mathrm{~m}$. The length $x_{2}$ can also be calculated via the diagonal of the $\mathrm{CuO}_{2}$ unit area by $x_{2}^{2}=\left(z_{5} a \sqrt{ } 2\right)^{2}+\left(z_{6} a \sqrt{ } 2\right)^{2}=(8+50) a^{2}$ with $z_{5}=2$ and $z_{6}=5$. Both $\mathrm{CuO}_{2}$ planes have the same $\mathrm{Cu}^{3+}$-ion distribution but they are shifted to match the homogeneous oxygen distribution and current channels in both $\mathrm{CuO}_{2}$ planes as illustrated in Fig. 5. The final calculation with $n=2$ results in $\left(2 x_{2}\right)^{2} n^{-2 / 3} T_{\mathrm{c}}=2.75 \times 10^{-15} \mathrm{~m}^{2} \mathrm{~K}$.

\section{$6 \mathrm{Hg}-1223$}

Figure 6 shows the crystal structure of the unit cell for a single-phase $\mathrm{HgBa}_{2} \mathrm{Ca}_{2} \mathrm{Cu}_{3} \mathrm{O}_{8+\delta 3}(\mathrm{Hg}-1223)$ including the electronic configuration for the undoped and doped unit cells. As for $\mathrm{Hg}-1201$ and $\mathrm{Hg}-1212$ the oxygen excess atom can only serve one $\mathrm{CuO}_{2}$ plane to create $\mathrm{a} \mathrm{Cu}^{3+}$-ion. Therefore only $1 / 3$ of the homogeneously oxygen excess doping distribution with density $\left(\Sigma^{-1}\right)$ will be responsible for the $\mathrm{Cu}^{3+}$-ion distribution in each $\mathrm{CuO}_{2}$ plane. This requires a nearly perfect regular triangle doping structure for the oxygen excess atoms on top/bottom of the unit cell with side length $d_{3}$ as well as for the $\mathrm{Cu}^{3+}$-ion distribution in each $\mathrm{CuO}_{2}$ plane with side length $x_{3}$. But the center points of tetragonal unit cells cannot form a perfect regular triangle structure. Therefore we are looking for the closest solution with the condition that the $\mathrm{Cu}^{3+}$-ion distribution should be lined up in straight lines with equidistant $\mathrm{Cu}^{3+}$-ion positions.

The fact that only one of the four $\mathrm{Cu}$ atoms at the corner of a unit cell can be transformed into a $\mathrm{Cu}^{3+}$-ion the triangular pattern requires the consideration that for the distance

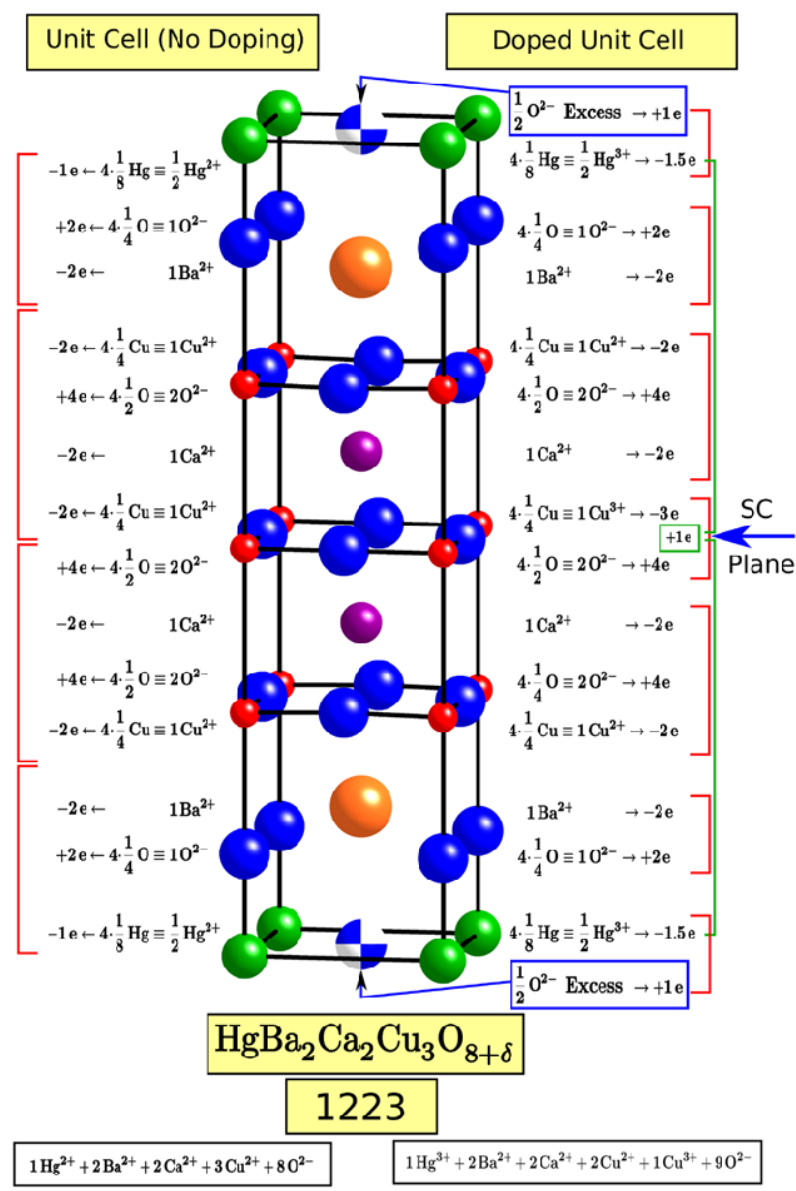

Fig. 6 Unit cell of $\mathrm{Hg}-1223$ illustrating the pure and oxygen doped electronic configuration. The $\mathrm{Cu}^{3+}$-ion will alternate between three $\mathrm{CuO}_{2}$ planes resulting in three superconducting $\mathrm{CuO}_{2}$ planes

between two doped unit cells a position shift should be taken into account so that a position shift so that $\mathrm{Cu}^{3+}$-ion must 


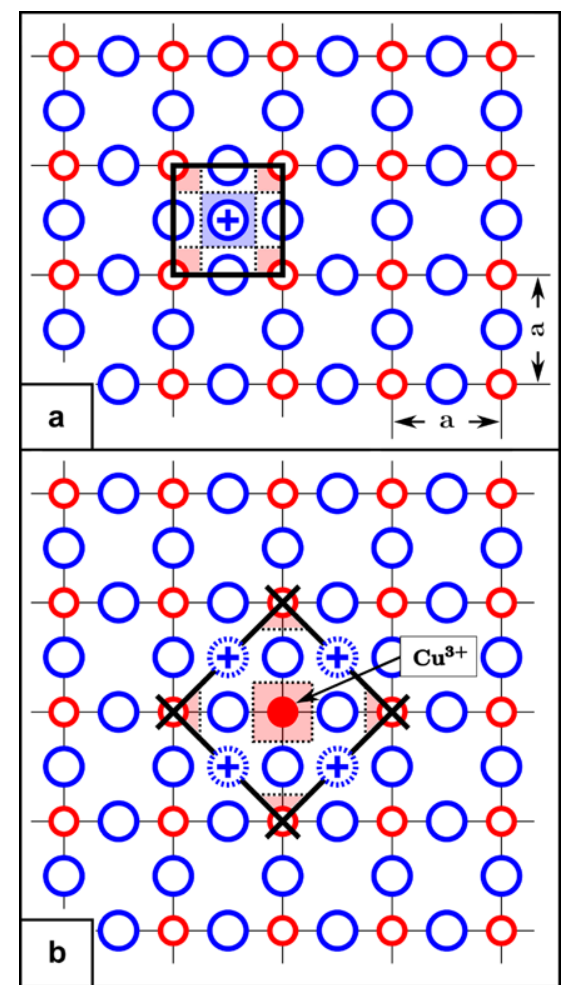

Fig. 7 The positions of $\mathrm{Cu}^{3+}$-ions in the $\mathrm{CuO}_{2}$ plane and oxygen excess atoms at top/bottom of the unit cell relative to each other. (a) For a doped unit cell there exist four possible $\mathrm{Cu}^{3+}$-ion positions at the corners. Each of them lies within an area of $(a / 4)^{2}$ given by the different ionic radii of $\mathrm{R}\left(\mathrm{O}^{2-}\right) \approx 0.125 \mathrm{~nm}$ and $\mathrm{R}\left(\mathrm{Cu}^{3+}\right) \approx 0.07 \mathrm{~nm}$. (b) For a given $\mathrm{Cu}^{3+}$-ion position the oxygen excess atom can be located in one of four neighboring unit cells

lay within the area $(a / 4)^{2}$ (Fig. 7). In an ideal case the unit area for the oxygen excess distribution $\left(A_{\text {Oxy }}\right)$ is given by two regular triangles with four oxygen doped unit cells at the corners and an area of $A_{\text {Oxy }}=\sqrt{ }(3 / 4)\left(d_{3}\right)^{2}=\sqrt{ }(3 / 4)\left(z_{1}^{2}+\right.$ $\left.z_{2}^{2}\right)(a / 4)^{2}$ or calculated via the diagonal of the $\mathrm{CuO}_{2}$ plane $\left(d_{3}\right)^{2}=\left(z_{3}^{2}+z_{4}^{2}\right)(a \sqrt{ } 2 / 4)^{2}$ with $z_{1}, z_{2}=0,1,2, \ldots$ The oxygen excess density $\left(\Sigma^{-1}\right)$ is defined as the ratio between $a^{2}$ and $A_{\text {Oxy }}$ with $\Sigma=\sqrt{ }(3 / 4)\left(z_{1}^{2}+z_{2}^{2}\right)$. The $\mathrm{Cu}^{3+}$-ion distance $x_{3}$ is given by $x_{3} \approx \sqrt{ } 3 d_{3}$ with a superconducting unit area of $A_{\mathrm{SC}} \approx \sqrt{ }(3 / 4)\left(x_{3}\right)^{2} \approx 3 / 2 d_{3} x_{3}$.

An optimum doping level $\delta_{3}$ between 0.33 and 0.41 associated with a transition temperature range of $T_{\mathrm{c}}=134 \pm 2 \mathrm{~K}$ has been reported [6,11-13]. The large range of $\delta_{3}=0.37 \pm$ 0.04 is probably caused by a broad bell-shaped form.

The oxygen excess doping density results in $\Sigma^{-1}=$ $8.37 / 8-1=4.6 \times 10^{-2} \equiv 4.6 \%$ with a separation of $d_{3}=5 a$ given by $d_{3}^{2}=\left(z_{1}^{2}+z_{2}^{2}\right) a^{2} \approx 25 a^{2}$. Figure 8 illustrates the numerical best solution for $d_{3}^{2}=\left(3.5^{2}+3.5^{2}\right) a^{2}=$ $(3.5 a \sqrt{ } 2)^{2}=24.5 a^{2}$ with $d_{3}=4.95 a$ and $x_{3}=\sqrt{ } 3 d_{3}=$ $8.57 a \approx 8.5 a=3.27 \times 10^{-9} \mathrm{~m}$.

The final calculation with $n=3$ results in $\left(2 x_{3}\right)^{2} \times$ $n^{-2 / 3} T_{\mathrm{c}}=2.76 \times 10^{-15} \mathrm{~m}^{2} \mathrm{~K}$.

\section{$7 \mathrm{Hg}-1234, \mathrm{Hg}-1245$ and Hg-1256}

The rise in $T_{\mathrm{c}}$ with the number of superconducting $\mathrm{CuO}_{2}$ planes up to $n=3$ stimulated research groups to synthesize $\mathrm{Hg}-1234, \mathrm{Hg}-1245$ and $\mathrm{Hg}-1256$ with $n=4,5$ and 6 $\mathrm{CuO}_{2}$ planes per unit cell. Experimental results demonstrated $[6,11]$ that

(a) it is very difficult to synthesize pure single phases for $n>3$,
Fig. 8 Red and filled circles represent the $\mathrm{Cu}^{3+}$-ion distribution in the upper $\mathrm{CuO}_{2}$ plane, green and slightly shaded circles represent the $\mathrm{Cu}^{3+}$-ion distribution in the middle and blue and open circles in the lower $\mathrm{CuO}_{2}$ plane of $\mathrm{Hg}-1223$. All together represent the oxygen excess distribution in the $\mathrm{Hg}$ plane separated by $d_{3}$. The $\mathrm{Cu}^{3+}$-ion separation is given by $x_{3} \approx \sqrt{ } 3 d_{3}$

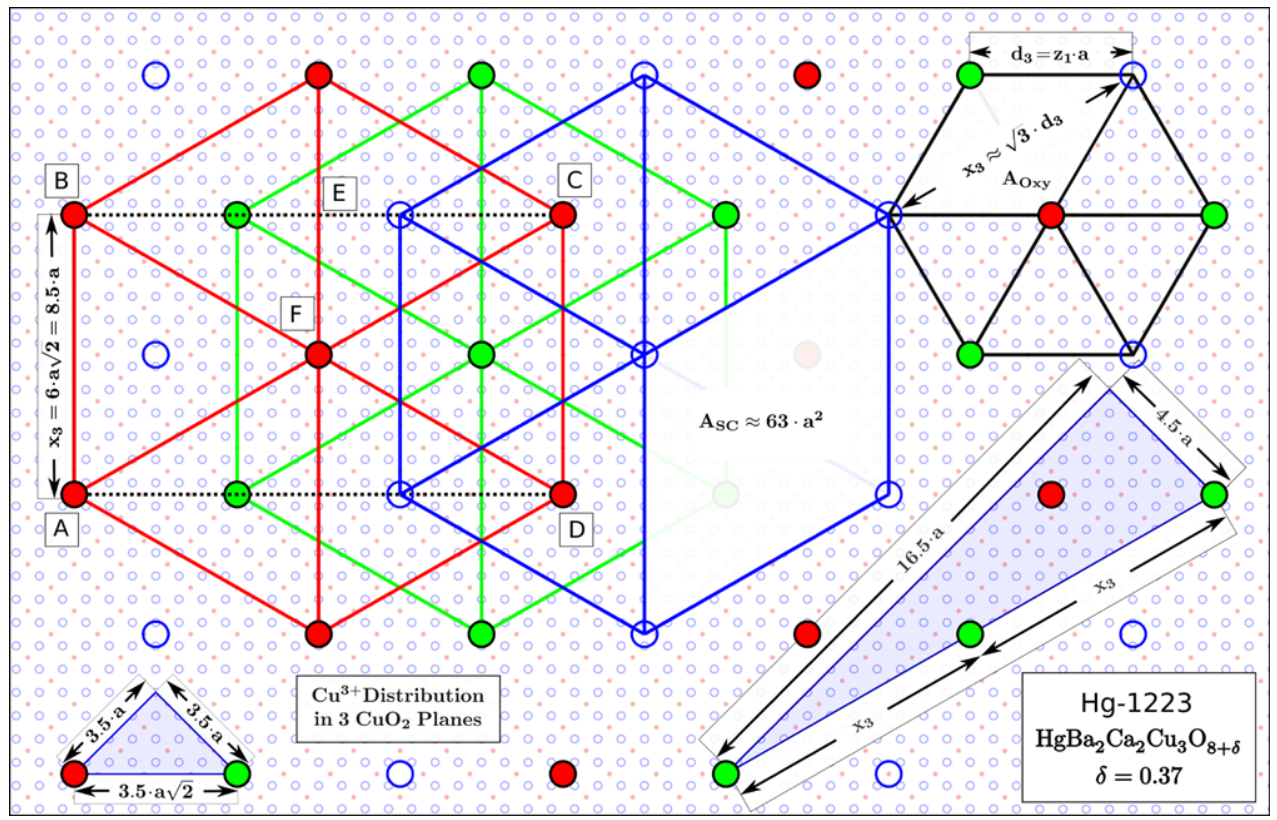


Fig. 9 Experimental data of optimum doping level $\delta$ for maximum $T_{\mathrm{c}}$ for $\mathrm{Hg}-1201$, $\mathrm{Hg}-1212$ and $\mathrm{Hg}-1223$

\begin{tabular}{|c|c|c|c|c|c|c|c|}
\hline \multirow{2}{*}{ MATERIAL } & \multirow{2}{*}{$\begin{array}{l}T_{C}[K] \\
\text { (exp.) }\end{array}$} & \multirow{2}{*}{$\begin{array}{c}\text { Crystal } \\
\text { Structure } \\
\text { tet }[\mathrm{nm}]\end{array}$} & \multicolumn{3}{|c|}{ Oxygen Excess } & \multirow{2}{*}{$\begin{array}{c}\mathrm{CuO}_{2} \\
\text { Planes } \\
\mathbf{n} \\
\end{array}$} & \multirow{2}{*}{$\begin{array}{c}(2 x)^{2} \cdot n^{-2 / 3} \cdot T_{c} \\
m_{1}\left[m^{2} K\right] \cdot 10^{-15}\end{array}$} \\
\hline & & & $\delta$ & $\begin{array}{c}\Sigma^{-1} \\
{[\%]}\end{array}$ & $\begin{array}{c}\mathbf{x} \\
{[\mathbf{n m}]}\end{array}$ & & \\
\hline $\begin{array}{c}\mathrm{HgBa}_{2} \mathrm{CuO}_{4+\delta} \\
\mathrm{Hg}-1201\end{array}$ & $95 \pm 1$ & $\begin{array}{l}a=0.388 \\
c=0.950\end{array}$ & $\begin{array}{l}\mathbf{0 . 0 8 2 5} \\
\pm 0.005\end{array}$ & 2.0 & $\begin{array}{l}2.71 \\
\pm 0.1\end{array}$ & 1 & 2.79 \\
\hline $\begin{array}{c}\mathrm{HgBa}_{2} \mathrm{CaCu}_{2} \mathrm{O}_{6+\delta} \\
\mathrm{Hg}-1212\end{array}$ & $126 \pm 1.5$ & $\begin{array}{l}a=0.386 \\
c=1.265\end{array}$ & $\begin{array}{c}0.21 \\
\pm 0.01\end{array}$ & 3.5 & $\begin{array}{l}2.94 \\
\pm 0.1\end{array}$ & 2 & 2.75 \\
\hline $\begin{array}{c}\mathrm{HgBa}_{2} \mathrm{Ca}_{2} \mathrm{Cu}_{3} \mathrm{O}_{8+\delta} \\
\mathrm{Hg}-1223\end{array}$ & $134 \pm 2$ & $\begin{array}{l}a=0.385 \\
c=1.610\end{array}$ & $\begin{array}{c}0.37 \\
\pm 0.04\end{array}$ & 4.6 & $\begin{array}{l}3.27 \\
\pm 0.2\end{array}$ & 3 & 2.76 \\
\hline
\end{tabular}

Fig. 10 Correlation between doping distance $x$ and the inverse of the critical transition temperature $T_{\mathrm{c}}$ in HTSCs. The value $n$ is the number of superconducting $\mathrm{CuO}_{2}$ planes per chemical formula within a unit cell. The data for $\mathrm{Hg}$-HTSCs are analyzed in this work. All others are taken from [2, 3, 14 and references therein]

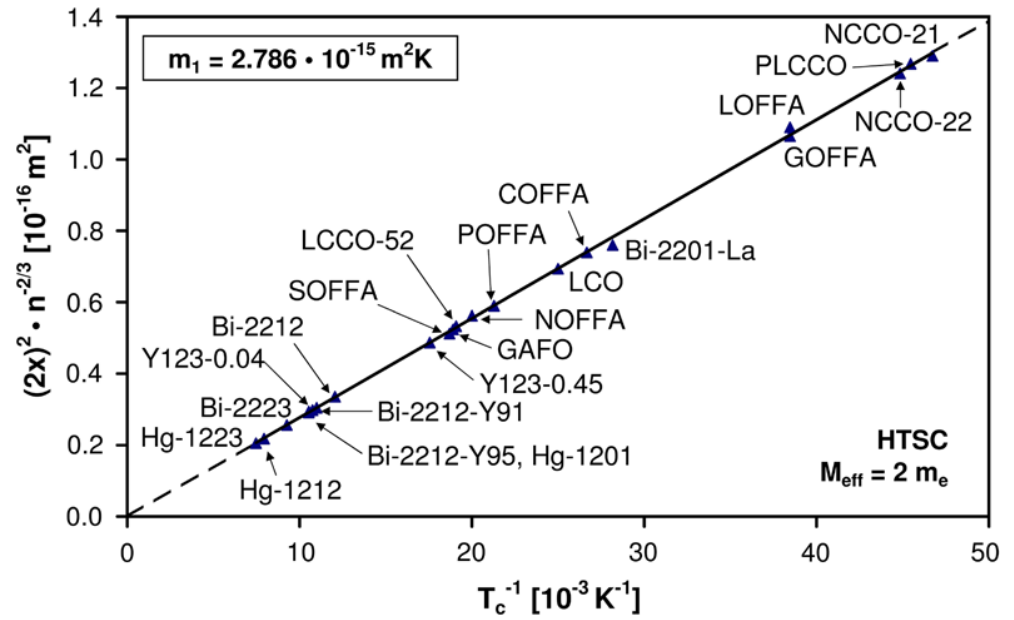

(b) they are superconducting but the transition temperature is decreasing to onset values of $T_{\mathrm{c}}=105 \mathrm{~K}(n=4)$, $T_{\mathrm{c}}=101 \mathrm{~K}(n=5)$ and $T_{\mathrm{c}}=95 \mathrm{~K}(n=6)$, and

(c) it has not been possible so far to increase the oxygen excess density compared to $\mathrm{Hg}-1223$ with $\delta=0.41$. In fact the doping reduced to $\delta=0.32$ for $\mathrm{Hg}-1245$ to achieve superconductivity at all.

Therefore there are no parabolic bell-shape curves available to determine the maximum $T_{\mathrm{c}}$ for optimum doping. According to Fig. 9 the optimum doping of HBCCO and $n>3$ for reaching the maximum of a bell-shaped curve should be well above $\Sigma^{-1} \equiv 5 \%(\delta \gg 0.4)$, which seems to be impossible to reach so far [6].

\section{P-type and N-type HTSCs}

Additionally to the mercury cuprate homologous series the authors have investigated different types of cuprates (p-type, n-type, with tetragonal as well as orthorhombic unit cell crystal structures, oxygen excess, oxygen deficiency, single and double doped devices) and iron-based HTSCs [2, 3, 14 and references therein]. The analysis demonstrates that also in other HTSC families the doping distance $x$ in the superconducting plane is a physical length of interest and shows a strong correlation to the inverse of the transition temperature $T_{\mathrm{c}}$ as illustrated in Fig. 10. The correlation can be written in the form

$$
(2 x)^{2} n^{-2 / 3}=m_{1} \frac{1}{T_{\mathrm{c}}}
$$

where $n$ is the number of superconducting planes, e.g. $\mathrm{CuO}_{2}$ planes in cuprates, per chemical formula within a unit cell. Using a weighted linear regression a straight line fits the data points with slope $m_{1}=(2.786 \pm 0.029) \times 10^{-15} \mathrm{~m}^{2} \mathrm{~K}$ in the range $20 \mathrm{~K} \leq T_{\mathrm{c}} \leq 134 \mathrm{~K}$ and a very small ordinate intercept value of $(-1.69 \pm 3.33) \times 10^{-19} \mathrm{~m}^{2}$. Comparing (5) and (6) with $M_{\text {eff }}=2 m_{\mathrm{e}}$ results in $f\left(k T_{\mathrm{c}}\right)=(3.133 \pm 0.033) k T_{\mathrm{c}} \approx$ $\pi k T_{\mathrm{c}}$ according to

$$
\frac{m_{1} k}{k T_{\mathrm{c}}}=\frac{h^{2}}{2 M_{\mathrm{eff}} f\left(k T_{\mathrm{c}}\right)}
$$

With the correlation curve in Fig. 10 (4) and (5) transform into

$$
(2 x)^{2} n^{-2 / 3} 2 M_{\mathrm{eff}} \pi k T_{\mathrm{c}} \approx h^{2}
$$

or

$$
\frac{(2 x)^{2} n^{-2 / 3} M_{\mathrm{eff}}}{h} \frac{k T_{\mathrm{c}}}{2} \approx \frac{\hbar}{2}
$$




\begin{tabular}{|c|c|c|c|}
\hline Material & $\begin{array}{l}T_{c}[K] \\
\text { exp. }\end{array}$ & $\begin{array}{l}(2 x)^{2} \cdot n^{-2 / 3} \\
{\left[10^{-18} \mathrm{~m}^{2}\right]}\end{array}$ & $\begin{array}{l}(2 x)^{2} \cdot n^{-2 / 3} \cdot T_{c} \\
{\left[10^{-15} \mathrm{~m}^{2} \mathrm{~K}\right]}\end{array}$ \\
\hline $\begin{array}{l}\mathrm{Nd}_{1.85} \mathrm{Ce}_{0.15} \mathrm{CuO}_{3.98} \\
\quad \mathrm{NCCO}-21\end{array}$ & $21.4 \pm 0.5$ & 129.0 & 2.762 \\
\hline $\begin{array}{c}\mathrm{Pr}_{0.88} \mathrm{LaCe}_{0.12} \mathrm{CuO}_{3.96} \\
\mathrm{PLCCO}\end{array}$ & $22 \pm 2$ & 126.8 & 2.789 \\
\hline $\begin{array}{l}\mathrm{Nd}_{1.84} \mathrm{Ce}_{0.16} \mathrm{CuO}_{3.98} \\
\quad \mathrm{NCCO}-22\end{array}$ & $22.3 \pm 0.5$ & 124.1 & 2.767 \\
\hline $\begin{array}{c}\mathrm{LaO}_{0.89} \mathrm{~F}_{0.11} \mathrm{FeAs} \\
\text { LOFFA }\end{array}$ & $26 \pm 1$ & 109.0 & 2.834 \\
\hline $\begin{array}{c}\mathrm{GdO}_{0.83} \mathrm{~F}_{0.17} \mathrm{FeAs} \\
\text { GOFFA }\end{array}$ & $26 \pm 1$ & 106.5 & 2.769 \\
\hline $\begin{array}{c}\mathrm{Bi}_{2} \mathrm{Sr}_{1.6} \mathrm{La}_{0.4} \mathrm{CuO}_{6.1} \\
\mathrm{Bi}-2201-\mathrm{La}\end{array}$ & $35.5 \pm 2.5$ & 76.0 & 2.699 \\
\hline $\begin{array}{c}\mathrm{CeO}_{0.84} \mathrm{~F}_{0.16} \mathrm{FeAs} \\
\text { COFFA }\end{array}$ & $37.5 \pm 1$ & 74.0 & 2.774 \\
\hline $\begin{array}{l}\mathrm{La}_{2} \mathrm{CuO}_{4.08} \\
\quad \mathrm{LCO}\end{array}$ & $40 \pm 1.5$ & 69.4 & 2.776 \\
\hline $\begin{array}{c}\mathrm{PrO}_{0.89} \mathrm{~F}_{0.11} \mathrm{FeAs} \\
\text { POFFA }\end{array}$ & $47 \pm 1$ & 59.0 & 2.772 \\
\hline $\begin{array}{c}\mathrm{NdO}_{0.89} \mathrm{~F}_{0.11} \mathrm{FeAs} \\
\text { NOFFA }\end{array}$ & $50 \pm 1$ & 56.3 & 2.813 \\
\hline $\begin{array}{l}\mathrm{La}_{1.82} \mathrm{Ca}_{1.18} \mathrm{Cu}_{2} \mathrm{O}_{6.02} \\
\text { LCCO-52 }\end{array}$ & $52.4 \pm 2$ & 53.3 & 2.794 \\
\hline $\begin{array}{l}\mathrm{GdFeAsO}_{0.85} \\
\text { GAFO }\end{array}$ & $52.9 \pm 0.6$ & 52.4 & 2.773 \\
\hline $\begin{array}{l}\mathrm{SmO}_{0.9} \mathrm{~F}_{0.1} \mathrm{FeAs} \\
\text { SOFFA }\end{array}$ & $53.5 \pm 1$ & 51.3 & 2.743 \\
\hline $\begin{array}{l}\mathrm{YBa}_{2} \mathrm{Cu}_{3} \mathrm{O}_{6.55} \\
\mathrm{Y} 123-0.45\end{array}$ & $57 \pm 2$ & 48.7 & 2.777 \\
\hline $\begin{array}{c}\mathrm{Bi}_{2} \mathrm{Sr}_{2} \mathrm{CaCu}_{2} \mathrm{O}_{8.18} \\
\mathrm{Bi}-2212\end{array}$ & $83 \pm 1$ & 33.6 & 2.786 \\
\hline $\begin{array}{c}\mathrm{Bi}_{2} \mathrm{Sr}_{2} \mathrm{Ca}_{0.92} \mathrm{Y}_{0.08} \mathrm{Cu}_{2} \mathrm{O}_{8.16} \\
\mathrm{Bi}-2212-\mathrm{Y}_{91}\end{array}$ & $91 \pm 1$ & 30.5 & 2.773 \\
\hline $\begin{array}{c}\mathrm{YBa}_{2} \mathrm{Cu}_{3} \mathrm{O}_{6.96} \\
\mathrm{Y} 123-0.04\end{array}$ & $93 \pm 1$ & 29.8 & 2.772 \\
\hline $\begin{array}{c}\mathrm{HgBa}_{2} \mathrm{CuO}_{4+\delta} \\
\mathrm{Hg}-1201\end{array}$ & $95 \pm 1$ & 29.4 & 2.791 \\
\hline $\begin{array}{c}\mathrm{Bi}_{2} \mathrm{Sr}_{2} \mathrm{Ca}_{1-\Delta} \mathrm{Y}_{\Delta} \mathrm{Cu}_{2} \mathrm{O}_{8+\delta} \\
\mathrm{Bi}-2212-\mathrm{Y} 95\end{array}$ & $95 \pm 1$ & 29.2 & 2.770 \\
\hline $\begin{array}{c}\mathrm{Bi}_{2} \mathrm{Sr}_{2} \mathrm{Ca}_{2} \mathrm{Cu}_{3} \mathrm{O}_{10.22} \\
\mathrm{Bi}-2223\end{array}$ & $108 \pm 2$ & 25.6 & 2.767 \\
\hline $\begin{array}{c}\mathrm{HgBa}_{2} \mathrm{CaCu}_{2} \mathrm{O}_{6+\delta} \\
\mathrm{Hg}-1212\end{array}$ & $126 \pm 1.5$ & 21.8 & 2.744 \\
\hline $\begin{array}{c}\mathrm{HgBa}_{2} \mathrm{Ca}_{2} \mathrm{Cu}_{3} \mathrm{O}_{8+\delta} \\
\mathrm{Hg}-1223\end{array}$ & $134 \pm 2$ & 20.6 & 2.755 \\
\hline
\end{tabular}

Fig. 11 Experimental data of high-temperature superconductor materials with optimum doping for maximum transition temperature $T_{\mathrm{c}}$. The analysis of Hg-based HTSCs is described in this work. Other materials are analyzed in $[2,3,14]$ and references therein using the same procedure
In this respect the theoretical value for the slope $m_{1}$ could be given by

$m_{1} \approx \frac{h^{2}}{2 \pi k M_{\mathrm{eff}}} \approx 2.778 \times 10^{-15} \mathrm{~m}^{2} \mathrm{~K}$

\section{Discussion}

Considering a particle with mass $M$, which is confined inside a box of width $x$, its wave function satisfies the freeparticle Schrödinger equation. Confinement of a particle may be interpreted as a standing wave in which an integer number $(n=1,2, \ldots)$ of half-wavelengths must fit into the box $n 1 / 2 \lambda_{\mathrm{dB}}=x$, where $\lambda_{\mathrm{dB}}=h / p$ represents de Broglie wavelength of the particle [1]. This results in $p=h / \lambda_{\mathrm{dB}}=$ $(n h) /(2 x)$ and the kinetic energy $E_{\text {kin }}$ for the standing wave, a solution of the time-independent Schrödinger equation, is given by

$E_{n}(\mathrm{PiB})=\frac{p^{2}}{2 M}=\frac{n^{2} h^{2}}{8 M x^{2}}$

Comparing (8) and (10) it looks like that the lowest energy level $E_{1}(\mathrm{PiB})$ of the superconducting carrier with $M=$ $M_{\text {eff }}=2 m_{\mathrm{e}}$ is connected to the transition temperature $T_{\mathrm{c}}$ by $E_{1}=\pi k T_{\mathrm{c}}$.

To prove that (8) is universally applicable more HTSC families should be investigated e.g. the thallium homologous series with oxygen excess and deficiency and the strontium series with infinite layer structures. Up to now, more than 20 different HTSC materials match the linear curve quite well (Fig. 11).

So far it is not possible to predict new HTSC candidates with much higher $T_{\mathrm{c}}$ because (8) contains two free parameters, $x$ and $T_{\mathrm{c}}$. And it is not known which one determines the exact location on the linear graph, because for all materials there exist only one optimum value for $x$ or $T_{\mathrm{c}}$ respectively.

It is of interest to note that conventional superconductors $\mathrm{Nb}, \mathrm{V}, \mathrm{Ta}$ and $\mathrm{Hg}$ also show a strong correlation between the bond length $x$ and the inverse of the critical superconducting transition temperature $T_{\mathrm{c}}$ in the form $(2 x)^{2} N_{\text {eff }}=m_{2} 1 / T_{\mathrm{c}}$. Here $N_{\text {eff }}$ is the number of electrons in the outermost s-shell. The slope of the fitted straight line has a quite different value of $m_{2} \approx 3.0 \times 10^{-18} \mathrm{~m}^{2} \mathrm{~K}[15]$.

\section{Conclusion}

The mercury cuprate homologous series $\mathrm{HgBa}_{2} \mathrm{Ca}_{\mathrm{n}-1} \mathrm{Cu}_{n}$ $\mathrm{O}_{2 n+2+\delta}$ belongs to the oxygen excess doped HTSCs. The oxygen excess atom transforms a $\mathrm{Cu}^{2+}$-ion into a $\mathrm{Cu}^{3+}$-ion within a unit cell, which is responsible for the superconducting state in the $\mathrm{CuO}_{2}$ plane. Assuming a homogeneous doping distribution the doping density $\delta$ can be translated into a 
doping distance $x$ between doped unit cells. The same procedure can be applied to different types of cuprates (p-type, n-type, with tetragonal as well as orthorhombic unit cell crystal structures, oxygen excess, oxygen deficiency, single and double doped devices) and iron-based HTSCs. For more than 20 HTSCs the correlation between the doping distance $x$ and the critical transition temperature shows the very first link between $T_{\mathrm{c}}$ and the crystal structure and geometry in form of a straight line. The correlation could be interpreted as the lowest energy level of a particle in the box of width $x$ with the value $E_{1}=\pi k T_{\mathrm{c}}$ being the kinetic energy of a standing wave with wavelength $\lambda_{\mathrm{dB}}=2 x$.

Acknowledgements We would like to thank J. Vernerey, H. Hall and A. Bohr for discussions and valuable comments.

Open Access This article is distributed under the terms of the Creative Commons Attribution Noncommercial License which permits any noncommercial use, distribution, and reproduction in any medium, provided the original author(s) and source are credited.

\section{References}

1. Rohlf, J.W.: Modern Physics from $\alpha$ to $Z^{0}$. Wiley, New York (1994)
2. Roeser, H.P., Hetfleisch, F., Haslam, D.T., López, J.S., Stepper, M., Vernerey, J., Huber, F.M., von Schoenermark, M.F., Nikoghosyan, A.S.: Acta Astronaut. 66, 637-642 (2009)

3. Roeser, H.P., Haslam, D.T., Hetfleisch, F., López, J.S., von Schoenermark, M.F., Stepper, M., Huber, F.M., Nikoghosyan, A.S.: Acta Astronaut. 67, 546-552 (2010)

4. Putilin, S.N., Antipov, E.V., Chmaissem, O., Marezio, M.: Nature 362, 226-228 (1993)

5. Zhao, X., et al.: Adv. Mater. 18, 3243-3247 (2006)

6. Capponi, J.J., et al.: Physica C 235-240, 146-149 (1994)

7. Tsuchiya, T., Fueki, K.: Physica C 288, 47-56 (1997)

8. Fukuoka, A., et al.: Physica C 265, 13-18 (1996)

9. Radaelli, P.G., Wagner, J.L., Hunter, B.A., Beno, M.A., Knapp, G.S., Jorgensen, J.D., Hinks, D.D.: Physica C 216, 29-35 (1993)

10. Schilling, A., Cantoni, M., Guo, J.D., Ott, H.R.: Nature 363, 5658 (1993)

11. Chmaissem, O., et al.: Physica C 217, 265-272 (1993)

12. Kareiva, A., Barkauskas, J., Mathur, J.S.: J. Phys. Chem. Solids 61, 789-797 (2000)

13. Dai, P., Chaloumakos, B.C., Sun, G.F., Wong, K.W., Xin, Y., Lu, D.F.: Physics C 243, 201-206 (1995)

14. Huber, F.M., Roeser, H.P., von Schoenermark, M.F.: J. Phys. Soc. Jpn. 77(Suppl. C), 142-144 (2008)

15. Roeser, H.P., Haslam, D.T., López, J.S., Stepper, M., von Schoenermark, M.F., Huber, F.M., Nikoghosyan, A.S.: Acta Astronaut. 67, 1333-1336 (2010) 